\title{
Acromesomelic dysplasia, Maroteaux type
}

INSERM

\section{Source}

INSERM. (1999). Orphanet: an online rare disease and orphan drug data base.

Acromesomelic dysplasia, Maroteaux type. ORPHA:40

Acromesomelic dysplasia, Maroteaux type is an autosomal recessively inherited form of acromesomelic dysplasia (see this term) characterized by severe dwarfism (adult height $>120 \mathrm{~cm}$ ), both axial and appendicular involvement (shortening of the middle and distal segments of limbs and vertebral shortening), and with normal facial appearance and intelligence. It is a less severe form than acromesomelic dysplasia, Grebe type and acromesomelic dysplasia, Hunter-Thomson type (see these terms). 